\title{
Qual é a Contribuição da Nomeação Seriada Rápida para a Habilidade de Leitura e Escrita?: Evidência de Crianças e Adolescentes com e sem Dificuldades de Leitura
}

\author{
Cláudia Cardoso-Martins ${ }^{2}$ \\ Universidade Federal de Minas Gerais \\ Bruce F. Pennington \\ University of Denver, Colorado
}

\begin{abstract}
Resumo
O estudo investiga a correlação entre, por um lado, a nomeação seriada rápida e a consciência de fonemas e, por outro, diversas medidas de habilidade de leitura e escrita. Participaram do estudo 146 crianças e adolescentes norte-americanos, entre sete e 18 anos de idade. Aproximadamente metade dos participantes $(N=71)$ apresentava dificuldades de leitura. Os resultados sugerem que a nomeação seriada rápida contribui para a variação na habilidade de leitura e escrita independentemente da consciência de fonemas. Contudo, relativamente à consciência de fonemas, a nomeação seriada rápida apresenta uma contribuição modesta para a aprendizagem da leitura e da escrita em um sistema de escrita alfabético. Os resultados de análises adicionais sugerem que a habilidade subjacente à nomeação seriada rápida é particularmente importante para o desenvolvimento da habilidade de ler textos, rápida e acuradamente. Por outro lado, a consciência fonêmica é particularmente importante para o desenvolvimento da habilidade de ler através da codificação fonológica, ou seja, através da conversão das letras ou grupos de letras em seus sons correspondentes. Finalmente, houve pouca indicação de que o papel desempenhado pela nomeação seriada rápida e pela consciência de fonemas varie em função da idade ou da habilidade de leitura.

Palavras-chave: nomeação seriada rápida; consciência fonêmica; leitura e escrita.
\end{abstract}

\section{What is the Contribution of Rapid Serial Naming to Reading and Spelling Ability?: Evidence from Children and Adolescents with and without Reading Difficulties}

\begin{abstract}
The study investigates the relationship between rapid serial naming and phoneme awareness, and reading and spelling ability. Participants were 146 North-American children and adolescents varying in age from seven to 18 years. Approximately half of the participants $(N=71)$ had reading difficulties. The results suggest that rapid serial naming contributes variation to reading and spelling ability that is independent of the contribution of phoneme awareness. However, relative to this skill, rapid serial naming makes a rather modest contribution to learning to read and spell in an alphabetic writing system. Further analyses suggested that rapid serial naming is particularly important for the development of the ability to read texts rapidly and accurately, whereas phoneme awareness is particularly important for the development of the ability to read by phonological recoding, that is, by translating letters or group of letters into their phonological codes. Finally, there was little indication that the role played by either phoneme awareness or rapid serial naming interacts with age or reading ability.

Keywords: Rapid serial naming; phoneme awareness; reading and spelling.
\end{abstract}

\footnotetext{
${ }^{1}$ Endereço para correspondência: Universidade Federal de Minas Gerais, Caixa Postal 378, 30123-970, Belo Horizonte, MG. E-mail: cacau@fafich.ufmg.br

${ }^{2}$ Esta pesquisa foi possível graças a uma série de financiamentos concedidos ao segundo autor pelo National Institute of Mental Health (NIMH), pelo National Institute of Child Health and Development (NICHD), pela March of Dimes Foundation e pela Orton Dyslexia Society. As análises relatadas neste artigo, assim como a elaboração do manuscrito, foram realizadas durante um programa sabático realizado pela primeira autora na Universidade de Denver, Colorado, EUA. A primeira autora agradece à Coordenação de Aperfeiçoamento de Pessoal de Nível Superior (CAPES) e ao Laboratório de Neuropsicologia do Desenvolvimento do Departamento de Psicologia da Universidade de Denver, pelo apoio.
}

Parece haver pouca dúvida de que a habilidade de prestar atenção consciente aos sons da fala é necessária para a aquisição da leitura e da escrita em um sistema de escrita alfabético. Por exemplo, existe ampla evidência de que a consciência fonológica, avaliada antes do início da alfabetização, correlaciona-se estreitamente com o progresso posterior na aquisição da leitura e da escrita (para uma revisão da literatura, ver, por exemplo, Brady \& Shankweiler, 1991; Goswami \& Bryant, 1990). Além 
disso, os resultados de estudos de intervenção (Bradley \& Bryant, 1983; Lundberg, Frost \& Peterson, 1988; Torgesen, Morgan \& Davis, 1992) sugerem que o treinamento da consciência fonológica exerce um impacto positivo na aprendizagem da leitura e da escrita. Não é surpreendente, portanto, que indivíduos com dificuldades de leitura apresentem um déficit pronunciado em tarefas que avaliam a consciência dos segmentos fonêmicos da fala, tanto em relação a indivíduos da mesma idade cronológica, como em relação a indivíduos mais jovens com o mesmo nível de leitura (Bruck, 1991; Pennington, Van Orden, Smith, Green \& Haith, 1990; Stanovich, 1994; Stanovich \& Siegel, 1994).

Recentemente, Maryanne Wolf e Patricia Bowers (Bowers \& Wolf, 1993; Wolf \& Bowers, 1999) sugeriram que a habilidade de processar símbolos visuais rapidamente também desempenha um papel importante na aprendizagem da leitura e da escrita em uma ortografia alfabética, e que uma desordem nessa habilidade constitui um segundo déficit na dislexia de evolução, independente do déficit na consciência de fonemas. De fato, embora déficits na consciência fonêmica co-ocorram freqüentemente com déficits na habilidade de processar símbolos visuais rapidamente, algumas crianças com dificuldades de leitura parecem apresentar déficits em apenas uma ou outra dessas habilidades (Wolf \& Bowers, 1999). Além disso, os resultados de um número relativamente grande de estudos mostram que a habilidade de processar símbolos visuais e a consciência fonêmica apresentam contribuições independentes para a variação na habilidade de leitura (Bowers, 1995; Manis, Seidenberg \& Doi, 1999; Olson, Forsberg \& Wise, 1994; Torgesen, Wagner, Rashotte, Burgess \& Hecht, 1997; Wagner e cols., 1997). Existe, com efeito, alguma indicação de que essas habilidades contribuem de maneira diferente para a aprendizagem da leitura e da escrita. Por exemplo, os resultados de alguns estudos (Bowers, 1995; Manis e cols., 1999) sugerem que a consciência fonêmica associa-se mais intimamente ao desenvolvimento da habilidade de codificação fonológica, isso é, da habilidade de ler através da codificação das letras ou grupos de letras em seus sons correspondentes, enquanto que o desenvolvimento da habilidade de codificação ortográfica, ou seja, a habilidade de aprender a ortografia correta das palavras, correlaciona-se sobretudo com a habilidade de processar símbolos visuais rapidamente. É possível que essa habilidade também se correlacione estreitamente com a habilidade de compreensão da leitura (Bowers, 1995) e com a habilidade de ler textos rápida e corretamente (Cornwall, 1992; Morris e cols., 1998).
A habilidade de processar símbolos visuais rapidamente é usualmente avaliada por intermédio de tarefas de nomeação seriada rápida. Nessas tarefas, avaliase o tempo gasto pelo participante para nomear uma série de estímulos visuais familiares - por exemplo, letras, dígitos, ou cores - o mais rapidamente possível. Uma vez que a rapidez é também um fator importante para a leitura textual fluente, não é surpreendente que o desempenho em tarefas de nomeação seriada rápida correlacione-se com o desempenho em medidas de leitura fluente de textos. Por sua vez, a correlação entre a nomeação seriada rápida e medidas de compreensão da leitura poderia ser explicada em função da correlação entre aquela habilidade e a leitura textual fluente. Afinal, quanto maior a habilidade de reconhecer palavras escritas rápida e acuradamente, maior a quantidade de recursos intelectuais disponíveis para a tarefa de compreensão da leitura.

Por outro lado, a hipótese de uma conexão especial entre a nomeação serial rápida e a habilidade de codificação ortográfica não parece tão óbvia. Não há dúvida de que a habilidade de formar representações ortográficas das palavras é importante para o seu reconhecimento correto e rápido. Essa habilidade parece especialmente importante no caso de palavras cujas ortografias contém relações letra-som irregulares e que, portanto, não podem ser lidas com base apenas na habilidade de codificação fonológica. Com base nesse tipo de consideração, Manis e colaboradores (1996) sugeriram que a relação entre medidas de nomeação seriada rápida e medidas de codificação ortográfica (por exemplo, a habilidade de ler palavras irregulares ou a habilidade de distinguir entre palavras homófonas como, por exemplo, concerto e conserto ou chá e $x a$ ) poderia ser explicada em termos do fato de que, tanto a habilidade de nomear séries de estímulos rapidamente, como a habilidade de reconhecer palavras irregulares e homófonas, envolve a habilidade de aprender relações símbolo-nome arbitrárias. Não é claro, contudo, em que a nomeação seriada rápida diferiria de outras medidas da habilidade de aprender relações símbolo-nome arbitrárias como, por exemplo, medidas do vocabulário produtivo ou do conhecimento dos nomes das letras. De fato, no estudo de Wagner e colaboradores (1997), a correlação entre a nomeação seriada rápida, avaliada quando as crianças estavam no jardim de infância (kindergarten), e a habilidade subsequente de leitura, desapareceu quando os autores controlaram o efeito de variações no conhecimento dos nomes das letras no início do estudo. Além disso, a existência de uma relação especial entre a nomeação seriada rápida - em oposição à 
consciência de fonemas - e a habilidade de codificação ortográfica não tem sido substanciada unanimemente (Olson e cols., 1994; Torgesen e cols., 1997). Por exemplo, no estudo de Olson e colaboradores (1994), a habilidade de nomeação seriada rápida não se correlacionou de forma especial com as medidas utilizadas para avaliar o conhecimento da ortografia das palavras. De fato, aquela habilidade correlacionou-se de forma igualmente modesta com as medidas que Olson e colaboradores utilizaram para avaliar a habilidade de codificação ortográfica e a habilidade de codificação fonológica.

Além dessas dificuldades, várias questões permanecem em relação à importância da nomeação seriada rápida em diferentes etapas da aprendizagem da leitura. Por exemplo, Bowers (1995) sugeriu que a habilidade de processar estímulos visuais rapidamente deveria ser particularmente importante no período compreendido entre a terceira e a quinta série do Ensino Fundamental, uma vez que é justamente nesse período que observa-se um desenvolvimento acelerado das representações ortográficas. Os resultados do estudo longitudinal de Torgesen e colaboradores (1997) são, aparentemente, consistentes com essa hipótese. Torgesen e colaboradores examinaram a correlação entre variações na consciência fonêmica e na nomeação seriada rápida e o desenvolvimento subsequente de vários aspectos da leitura, em dois períodos sobrepostos: da segunda à quarta série e da terceira à quinta série. De acordo com Torgesen e colaboradores, ao contrário do que ocorreu para o período compreendido entre a segunda à quarta séries, variações na nomeação rápida na terceira série - em oposição às variações na consciência de fonemas correlacionaram-se com variações nas medidas de codificação ortográfica administradas quando as crianças estavam na quinta série. Entre as crianças com dificuldades de leitura, a nomeação seriada rápida na terceira série também contribuiu mais variação para uma medida de habilidade de leitura de palavras isoladas na quinta série do que a consciência de fonemas. Por outro lado, os resultados de análises calculadas para as mesmas crianças nos períodos compreendidos entre o jardim de infância e a segunda série, a primeira e a terceira série e, finalmente, a segunda e a quarta série (Wagner e cols., 1997) sugerem exatamente o contrário, ou seja, que a importância da nomeação seriada rápida pode estar limitada às fases iniciais da aquisição da leitura. De acordo com Wagner e colaboradores (1997), a nomeação rápida mostrou-se importante para o desenvolvimento subsequente da leitura de palavras isoladas apenas nos dois primeiros períodos de desenvolvimento investigados. McBride-Chang e Manis (1997) também sugeriram que

Psicologia: Reflexão e Crítica, 2001, 14(2), pp. 387-397 a nomeação seriada rápida pode ser mais importante nas fases iniciais da aquisição da leitura. No seu estudo com crianças da terceira e quarta série, a nomeação seriada rápida só correlacionou-se significativamente com a habilidade de leitura entre os leitores com dificuldade; já a consciência fonêmica, por outro lado, correlacionou-se com a habilidade de leitura tanto entre os leitores com dificuldade como entre os bons leitores. Finalmente, Meyer, Wood, Hart e Felton (1998) sugeriram que, embora a habilidade subjacente à nomeação seriada rápida permaneça importante até pelo menos a 8 a série, sua importância restringe-se a crianças com dificuldades de leitura.

Este estudo é mais uma tentativa de avaliar a relação entre a nomeação seriada rápida e a habilidade de leitura e escrita. Várias características do estudo - em particular, a inclusão de leitores com uma margem ampla de habilidade de leitura e idade cronológica, assim como a avaliação de várias habilidades diferentes de leitura e escrita - tornam-no particularmente adequado para investigar algumas das questões mencionadas acima. Em particular, o estudo investiga se a nomeação seriada rápida e a consciência fonêmica contribuem de forma diferente para o desenvolvimento da leitura/escrita e, em que medida, essa contribuição varia em função da idade e da habilidade de leitura.

\section{Método}

\section{Participantes}

Cento e quarenta e seis crianças e adolescentes norteamericanos de classe média/média-alta, cuja idade variava entre sete e 18 anos, participaram do estudo. Aproximadamente metade dos participantes $(N=71)$ apresentava dificuldade de leitura, definida em função de dois critérios: uma história de problemas de leitura e escrita, e uma discrepância significativa entre a habilidade de leitura e/ou escrita e outras habilidades cognitivas. Esta discrepância foi avaliada através do quociente de leitura (reading quotient) ou do algoritmo específico de dislexia (specific dyslexic algorithym), ambos os quais definem a dislexia em função de uma discrepância entre a habilidade de leitura e o QI (ver Pennington, Lefly, Van Orden, Bookman \& Smith, 1987; e Pennington e cols., 1986, para uma descrição dessas medidas). Como pode ser visto na Tabela 1, os participantes com dificuldades de leitura apresentavam, em média, um quociente de leitura inferior a 0,80 , indicando uma discrepância significativa entre a sua habilidade de leitura real e a sua habilidade de leitura esperada. A maioria desses participantes também apresentava um nível de leitura abaixo do esperado para a sua idade cronológica ou nível de escolaridade. De fato, 
como pode ser visto na Tabela 1, o seu escore médio no Teste de Reconhecimento de Palavras (ver abaixo) era inferior ao escore que seria esperado para a sua série escolar. Por outro lado, os participantes sem dificuldade de leitura apresentavam quocientes de leitura em torno de 1,0, indicando a inexistência de uma discrepância entre a sua habilidade de leitura real e a sua habilidade de leitura esperada. Além disso, seus escores no teste de reconhecimento de leitura eram compatíveis ou superiores aos escores esperados para crianças e adolescentes do mesmo nível de escolaridade.

Apenas crianças e adolescentes com QI igual ou superior a 85 participaram. Além disso, nenhum
- Reconhecimento de Palavras (Dunn \& Markwardt, 1970). Esse teste avalia a habilidade de leitura de palavras isoladas. A tarefa do participante consiste em ler, em voz alta, palavras apresentadas em ordem crescente de dificuldade. Acredita-se que o teste envolva tanto a habilidade de codificação fonológica, como a habilidade de codificação ortográfica.

- Compreensão de Leitura (Dunn \& Markwardt, 1970). O teste avalia a habilidade de compreensão de sentenças isoladas, apresentadas em ordem crescente de dificuldade. O participante é instruído a ler cada sentença silenciosamente e, em seguida, escolher, entre quatro desenhos diferentes, aquele que melhor descreve o conteúdo da sentença.

Tabela 1. Descrição da Amostra

\begin{tabular}{|c|c|c|c|c|}
\hline \multirow{3}{*}{$\overline{M e d i d a}$} & \multicolumn{4}{|c|}{ Grupo } \\
\hline & \multicolumn{2}{|c|}{$\begin{array}{l}\text { Leitores com dificuldade } \\
\qquad(n=71)\end{array}$} & \multicolumn{2}{|c|}{$\begin{array}{l}\text { Leitores sem dificuldade } \\
\qquad(n=75)\end{array}$} \\
\hline & $m$ & $d p$ & $m$ & $d p$ \\
\hline Idade (Anos) & 12,45 & 2,94 & 11,45 & 2,97 \\
\hline Educação: Série Escolar & 6,90 & 2,85 & 5,87 & 2,88 \\
\hline WISC-R: QI Verbal & 105,93 & 11,48 & 115,76 & 11,01 \\
\hline WISC-R: QI de Desempenho & 107,82 & 12,03 & 110,27 & 12,71 \\
\hline Raven: IQ & 109,03 & 12,41 & 114,12 & 10,35 \\
\hline Quociente de Leitura & 0,74 & 0,10 & 1,02 & 0,13 \\
\hline $\begin{array}{l}\text { PIAT: Leitura de Palavras } \\
\text { (série escolar equivalente) }\end{array}$ & 5,07 & 3,06 & 7,87 & 3,40 \\
\hline
\end{tabular}

participante apresentava problemas não corrigidos de visão ou audição, ou uma história incluindo qualquer uma das seguintes condições: complicações perinatais graves, epilepsia ou qualquer outra desordem neurológica, e, finalmente, privação sócio-econômica. A Tabela 1 apresenta as principais características da amostra, separadamente para os leitores com e sem dificuldade.

\section{Medidas de Avaliação}

Os participantes foram submetidos a testes padronizados de inteligência e de leitura e escrita, assim como a tarefas experimentais desenvolvidas com o objetivo de avaliar o funcionamento de vários processos fonológicos - percepção de fonema, memória verbal de curto prazo, rapidez articulatória e consciência fonêmica - e da habilidade de recuperação lexical (seriada e discreta). Este artigo descreve apenas os resultados para os testes padronizados e para as tarefas experimentais de consciência fonêmica e recuperação lexical seriada.

\section{Habilidade de Leitura e Escrita}

Teste Peabody de Aptidão Individual (PIAT):
- Reconhecimento de Escrita (Dunn \& Markwardt, 1970). O teste avalia a habilidade de o indivíduo reconhecer a ortografia de palavras enunciadas pelo examinador. Para cada um dos itens do teste, o examinador enuncia uma palavra, primeiro isoladamente, depois em uma sentença e, por último, isoladamente mais uma vez. A tarefa do participante consiste em escolher, entre quatro ortografias semelhantes do ponto de vista ortográfico e fonológico, aquela que corresponde à palavra enunciada pelo examinador (por ex.., cloudy: clowdy, cloady, cloudey, cloudy). Como todos os itens envolvem pelo menos uma ortografia cuja pronúncia é idêntica à pronúncia da ortografia correta, acredita-se que esse teste seja uma medida adequada da habilidade de codificação ortográfica.

Teste Wide Range de Aptidão (WRAT): Produção de Escrita (Jastak \& Wilkinson, 1984). O teste avalia a habilidade de produção ortográfica. Duas versões do WRAT foram utilizadas: a versão 1 , para os participantes mais jovens e a versão 2, para os mais velhos. As palavras, ditadas em ordem de dificuldade, são enunciadas pelo examinador uma a uma, primeiro isoladamente, depois 
em uma sentença e, por último, isoladamente mais uma vez. Esse teste pode ser considerado como uma medida de codificação fonológica, uma vez que, em vários itens, a resposta correta pode ser produzida através da utilização de regras de correspondência fonema-grafema.

Teste Gray de Leitura Oral (Widerholt \& Bryant, 1992). O teste avalia a rapidez e a exatidão da leitura oral, as quais são combinadas para gerar um único escore. A tarefa do participante consiste em ler, em voz alta, o mais correta e rapidamente possível, textos de níveis crescentes de dificuldade.

Teste Woodcock-Johnson de Aptidão: Leitura de Pseudopalavras (Woodcock \& Mather, 1989). O teste avalia a habilidade de leitura de pseudopalavras pronunciáveis. Esse teste é uma boa medida da habilidade de codificação fonológica: uma vez que pseudopalavras não existem, elas não podem ser reconhecidas visualmente, só podendo ser lidas através da codificação fonológica.

\section{Testes de Inteligência}

Três medidas de QI são relatadas na Tabela 1: uma medida de QI verbal, uma medida de QI de desempenho e uma medida de inteligência fluida - o QI de Raven. O QI verbal e o QI de desempenho são provenientes da Escala Weschler de Inteligência Infantil - Revisada (Weschler, 1974) e o QI de Raven é proveniente do Teste de Matrizes Progressivas de Raven (Raven \& Summers, 1986).

\section{Tarefas de Consciência Fonêmica}

- Pig Latin. A tarefa avalia a habilidade de segmentar e manipular fonemas. A tarefa compõe-se de 48 palavras reais, as quais são apresentadas oralmente, uma de cada vez. Para cada uma das palavras, o participante era instruído a retirar o fonema inicial, transpô-lo para o final da palavra e, finalmente, adicionar o som ay (por exemplo, para a palavra pig, a resposta correta é igpay).

- Inversão de fonemas: Como o Pig Latin, a tarefa de inversão de fonemas é uma medida da habilidade de segmentar e manipular fonemas. A tarefa consiste de 24 palavras, as quais são apresentadas, uma de cada vez, em duas condições. Na condição de produção, o participante era instruído a repetir as palavras de trás para diante. $\mathrm{Na}$ condição de reconbecimento, sua tarefa consistia em identificar, entre duas palavras diferentes, aquela que correspondia ao inverso da palavra enunciada pelo examinador. Em todos os itens, a alternativa incorreta era fonologicamente semelhante à alternativa correta e continha apenas um único fonema incorreto.

\section{Nomeação Seriada Rápida}

Dois testes foram utilizados para avaliar a nomeação seriada rápida: o Teste de Nomeação Automatizada Rápida (Rapid Automatized Naming - RAN), desenvolvido por Denckla e Rudel (1976) e o Teste de Alternação Rápida de Estimulo (Rapid Alternating Stimulus - RAS), desenvolvido por Wolf, Bally e Morris (1986). O RAN consiste de quatro conjuntos de estímulos, os quais aparecem impressos em 5 fileiras de 10 itens cada. Os quatro conjuntos de estímulos são: 1) letras minúsculas (a, d, o, s, p); 2) números $(2,4,6,7,9)$; 3) cores (vermelho, amarelo, verde, azul, preto); e, 4) desenhos de objetos comuns (guarda-chuva, tesoura, pente, relógio, chave). Os estímulos em cada conjunto são apresentados em ordem aleatória, em um total de 10 vezes cada um.

O RAS é semelhante ao RAN, com exceção de que os seus dois conjuntos envolvem estímulos de diferentes categorias (letras, números e cores, em um conjunto e letras e números, no segundo).

\section{Procedimento}

Todos os participantes foram testados individualmente no Laboratório de Neuropsicologia do Desenvolvimento da Universidade de Denver, nos Estados Unidos da América. Os testes de inteligência, leitura e escrita foram administrados conforme o procedimento padrão. Itens de treinamento com feedback foram administrados antes das tarefas de consciência fonêmica para assegurar a compreensão da tarefa pelo participante. No Pig Latin, o participante era encorajado a responder o mais rápida e corretamente possível. A administração do teste foi gravada. A exatidão das respostas foi anotada durante $o$ teste e, posteriormente, confirmada com base na gravação.

O teste de inversão de fonemas foi administrado após o Pig Latin. O participante escutava uma palavra (por exemplo, team) e era instruído a dizer a palavra de trás para diante. Após a sua resposta, o participante ouvia a gravação de duas palavras (por exemplo, meat e meak) e devia dizer qual delas correspondia à resposta correta. As respostas do participante eram anotadas e classificadas quanto à sua exatidão no decorrer do exame.

Nos testes RAN e RAS, o participante era instruído a nomear os itens em cada conjunto de cima para baixo e da esquerda para a direita, o mais rapidamente possível. Itens de treinamento eram administrados para cada um dos conjuntos, para assegurarmos-nos de que o participante podia identificar todos os itens. Tanto a latência como a exatidão das respostas foi anotada pelo examinador. No entanto, uma vez que a exatidão das respostas foi muita elevada em todos os conjuntos (97- 
99\%), a variável de interesse consistiu no tempo gasto para nomear os estímulos em cada conjunto.

\section{Resultados}

A Tabela 2 apresenta a proporção média (e o desviopadrão) de respostas corretas para os diversos testes de leitura e escrita, separadamente para os participantes com e sem dificuldades de leitura. Os resultados para as medidas de consciência fonêmica e de nomeação seriada rápida aparecem nas Tabelas 3 e 4, respectivamente. Como pode ser visto nessas tabelas, ambos os grupos de participantes variaram consideravelmente em todas as medidas. As análises descritas a seguir foram calculadas com o objetivo de avaliar em que medida as variações nas tarefas experimentais contribuíram para as variações nos testes de leitura e escrita. Para essas análises, os escores nas medidas experimentais foram estandardizados em função do desempenho de toda a amostra (2). Escores compostos de consciência fonêmica e de nomeação seriada rápida - correspondendo à média (reestandardizada) dos escores estandardizados em cada tarefa pertinente - foram criados. Uma vez que escores brutos individuais de habilidade de leitura e escrita foram usados nessas análises, não havia necessidade de estandardizá-los.

Tabela 2. Testes de Leitura e Escrita: Proporção Correta (No. Itens corretos/total de itens)

\begin{tabular}{lcccc}
\hline \multirow{2}{*}{ Testes } & \multicolumn{4}{c}{ Grupo } \\
\hline \multirow{2}{*}{ PIAT: Leitura de Palavras } & $m$ & $d p$ & $m$ & $d p$ \\
\cline { 2 - 5 } PIAT: Compreensão de Leitura & 0,53 & 0,17 & 0,65 & 0,18 \\
PIAT: Reconhecimento de Escrita & 0,57 & 0,18 & 0,64 & 0,17 \\
WRAT: Produção de Escrita & 0,48 & 0,14 & 0,61 & 0,18 \\
Gray Oral: Fluência de Leitura & 0,32 & 0,17 & 0,52 & 0,17 \\
Woodcock-Johnson: Leitura de & 0,25 & 0,17 & 0,44 & 0,22 \\
Pseudopalavras & 0,54 & 0,26 & 0,79 & 0,22 \\
\hline
\end{tabular}

Tabela 3. Tarefas de Consciência Fonêmica: Proporção correta (No. Itens corretos/total de itens)

\begin{tabular}{lcccc}
\hline Tarefas & \multicolumn{4}{c}{ Grupo } \\
\hline & Leitores com & dificuldade & \multicolumn{2}{c}{ Leitores sem dificuldade } \\
& $m$ & $d p$ & $m$ & $d p$ \\
\cline { 2 - 5 } Pig Latin & 45,81 & 28,91 & 69,13 & 24,52 \\
Inversão de Fonemas: Produção & 49,01 & 32,76 & 72,80 & 24,03 \\
Inversão de Fonemas: Reconhecimento & 81,11 & 21,73 & 92,93 & 10,79 \\
\hline
\end{tabular}

Tabela 4. Tarefas de Nomeação Seriada Rápida: Latência em Segundos (Média e Desvio Padrão)

\begin{tabular}{lcccr}
\hline & \multicolumn{5}{c}{ Grupo } \\
\hline Tarefas & Leitores com dificuldade & \multicolumn{2}{c}{ Leitores sem dificuldade } \\
& $m$ & $d p$ & $m$ & \multicolumn{1}{c}{$\boldsymbol{c} p$} \\
\hline RAN: Cor & 41,31 & 14,66 & 40,32 & 11,37 \\
RAN: Dígitos & 28,32 & 11,28 & 26,35 & 8,65 \\
RAN: Objetos & 54,51 & 18,24 & 51,21 & 15,68 \\
RAN: Letras & 28,87 & 9,22 & 26,31 & 8,88 \\
RAS: Dígitos e Letras & 34,27 & 12,15 & 31,39 & 11,35 \\
RAS: Dígitos, Letras e Cores & 40,24 & 16,89 & 36,23 & 12,38 \\
\hline
\end{tabular}


A Tabela 5 apresenta a matriz de correlações para as diferentes medidas empregadas e a idade cronológica. Os resultados dos participantes com e sem dificuldades de leitura aparecem acima e abaixo da diagonal, respectivamente. Conforme pode ser observado em ambos os grupos, o desempenho nas tarefas de de calcularmos as análises separadamente para os participantes com e sem dificuldades de leitura (ou para os participantes mais jovens e mais velhos), decidimos reunir todos os participantes e investigar o papel desempenhado pela habilidade de leitura e pela idade cronológica através da inclusão de um termo de interação

Tabela 5. Correlações entre Leitura e Escrita, Medidas Experimentais, QIs e Idade

\begin{tabular}{lcccccccccccc}
\hline & Idade & QI V & QI D & QI RAV & P-LP & P-CL & P-RE & W-PE & Gray Oral & W-JLP & CF & NSR \\
Idade & - & $-0,18$ & $-0,08$ & $-0,27^{*}$ & $0,80^{* *}$ & $0,78^{* *}$ & $0,76^{* *}$ & $-0,54^{* *}$ & $0,73^{* *}$ & $0,58^{* *}$ & $0,52^{* *}$ & $-0,62^{* *}$ \\
QI V & $-0,12$ & - & $0,54^{* *}$ & $0,56^{* *}$ & 0,14 & 0,21 & 0,12 & $0,26^{*}$ & 0,11 & 0,17 & 0,05 & $-0,04$ \\
QI D & 0,14 & $0,43^{* *}$ & - & $0,29^{*}$ & 0,08 & 0,13 & 0,10 & 0,06 & 0,09 & 0,08 & $-0,02$ & $-0,12$ \\
QI RAV & $-0,25^{*}$ & $0,36^{* *}$ & $0,42^{* *}$ & - & $-0,07$ & $-0,06$ & $-0,01$ & 0,43 & $-0,09$ & $-0,02$ & $-0,04$ & 0,07 \\
P-LP & $0,85^{* *}$ & 0,08 & $0,28^{*}$ & $-0,06$ & - & $0,88^{* *}$ & $0,80^{* *}$ & $-0,22$ & $0,86^{* *}$ & 0,71 & $0,64^{* *}$ & $-0,69^{* *}$ \\
P-CL & $0,82^{* *}$ & 0,18 & $0,25^{*}$ & $-0,05$ & $0,87^{* *}$ & - & $0,77^{* *}$ & $-0,30^{*}$ & $0,86^{* *}$ & $0,64^{* *}$ & $0,64^{* *}$ & $-0,67^{* *}$ \\
P-RE & $0,86^{* *}$ & 0,12 & 0,22 & $-0,10$ & $0,89^{* *}$ & $0,88^{* *}$ & - & $0,30^{*}$ & $0,74^{* *}$ & $0,61^{* *}$ & $0,59^{* *}$ & $-0,69^{* *}$ \\
W-PE & $-0,33^{* *}$ & $0,26^{*}$ & $-0,00$ & $0,37^{* *}$ & $-0,07$ & $-0,09$ & $-0,09$ & - & $-0,21$ & $-0,17$ & $-0,003$ & 0,23 \\
Gray Oral & $0,87^{* *}$ & 0,08 & 0,21 & $-0,14$ & $0,87^{* *}$ & $0,84^{* *}$ & $0,87^{* *}$ & $-0,17$ & & $0,63^{* *}$ & $0,64^{* *}$ & $-0,76^{* *}$ \\
W-J LP & $0,60^{* *}$ & 0,04 & 0,13 & $-0,03$ & $0,79^{* *}$ & $0,72^{* *}$ & $0,72^{* *}$ & $0,26^{*}$ & $0,70^{* *}$ & - & $0,64^{* *}$ & $-0,54^{* *}$ \\
CF & $0,47^{* *}$ & 0,15 & 0,17 & 0,15 & $0,60^{* *}$ & $0,58^{* *}$ & $0,52^{* *}$ & 0,21 & $0,48^{* *}$ & $0,68^{* *}$ & - & $-0,54^{* *}$ \\
NSR & $-0,85^{* *}$ & $-0,02$ & $-0,19$ & 0,20 & $-0,82^{* *}$ & $-0,80^{* *}$ & $-0,75^{* *}$ & 0,22 & $-0,88^{* *}$ & $-0,63^{* *}$ & $-0,49^{* *}$ & - \\
\hline
\end{tabular}

$* p<0,01 ; * * p<0,001$.

Nota: Leitores com dificuldade: acima da diagonal; Leitores sem dificuldade: abaixo da diagonal.

P-LP: Piat-Leitura de Palavras; P-CL: Piat-Compreensão de Leitura; P-RE: Piat-Reconhecimento de Escrita; W-PE: WRAT- Produção de Escrita; Gray Oral: Fluência de Leitura; W-J LP: Woodcock-Johnson: Leitura de pseudopalavras; CF: Consciência fonêmica; NSR: Nomeação seriada rápida.

consciência fonêmica e de nomeação seriada rápida correlacionou-se significativamente com o desempenho em praticamente todos os testes de leitura e escrita. (3)

Análises hierárquicas de regressão foram calculadas com o objetivo de avaliar a especificidade da contribuição da consciência fonêmica e da nomeação seriada rápida para as diferentes habilidades de leitura e escrita. Em vez nas análises de regressão (ver abaixo). Além disso, como pode ser visto na Tabela 5, o padrão de correlações encontrado para os sujeitos com e sem dificuldades de leitura foi similar o bastante para justificar esse procedimento.

Duas análises de regressão foram calculadas para cada uma das medidas de leitura e escrita. Ambas as análises

Tabela 6. Análises de Regressão: A Contribuição da Consciência Fonêmica e da Nomeação Seriada Rápida para Várias Medidas de Leitura e Escrita

Variáveis

\begin{tabular}{|c|c|c|c|c|c|c|c|}
\hline \multirow[t]{2}{*}{ ndependentes $g l$} & \multicolumn{2}{|c|}{ Leitura de Palavras } & $\begin{array}{l}\text { Compreensão } \\
\text { de Leitura }\end{array}$ & $\begin{array}{l}\text { Reconhecimento } \\
\text { de Escrita }\end{array}$ & $\begin{array}{l}\text { Produção } \\
\text { de Escrita }\end{array}$ & $\begin{array}{c}\text { Gray Oral: } \\
\text { Fluência Verbal }\end{array}$ & $\begin{array}{c}\text { Leitura de } \\
\text { Pseudopalavras }\end{array}$ \\
\hline & $R$ & $\begin{array}{l}\text { Mudança } \\
e m \mathrm{R}^{2}\end{array}$ & $\begin{array}{c}\text { R Mudança } \\
\text { em } \mathrm{R}^{2}\end{array}$ & $\begin{array}{c}\mathrm{R} \quad \text { Mudança } \\
\text { em } \mathrm{R}^{2}\end{array}$ & $\begin{array}{c}\mathrm{R} \quad \text { Mudança } \\
\text { em } \mathrm{R}^{2}\end{array}$ & $\begin{array}{c}\mathrm{R} \quad \begin{array}{c}\text { Mudanca } \\
\text { em } \mathrm{R}^{2}\end{array}\end{array}$ & $\begin{array}{c}\mathrm{M} \text { Mudança } \\
\text { em } \mathrm{R}^{2}\end{array}$ \\
\hline
\end{tabular}

\begin{tabular}{llllllllllllll}
\hline Passos & & & & & & & & & & & & & \\
1) Idade & 1,140 & 0,710 & $0,504^{* *}$ & 0,732 & $0,536^{* *}$ & 0,672 & $0,452^{* *}$ & 0,461 & $0,212^{* *}$ & 0,638 & $0,407^{* *}$ & 0,417 & $0,174^{* *}$ \\
2) QIV & 1,139 & 0,807 & $0,148^{* *}$ & 0,841 & $0,171^{* *}$ & 0,786 & $0,165^{* *}$ & 0,564 & $0,106^{* *}$ & 0,750 & $0,156^{* *}$ & 0,555 & $0,134^{* *}$ \\
3) CF & 1,138 & 0,865 & $0,097^{* *}$ & 0,878 & $0,063^{* *}$ & 0,826 & $0,065^{* *}$ & 0,683 & $0,148^{* *}$ & 0,802 & $0,081^{* *}$ & 0,750 & $0,255^{* *}$ \\
4) NSR & 1,137 & 0,879 & $0,024^{* *}$ & 0,886 & $0,015^{*}$ & 0,838 & $0,019^{*}$ & 0,686 & 0,005 & 0,853 & $0,085^{* *}$ & 0,761 & $0,017^{*}$ \\
3) NSR & 1,138 & 0,844 & $0,060^{* *}$ & 0,863 & $0,037^{* *}$ & 0,814 & $0,045^{* *}$ & 0,594 & $0,035^{*}$ & 0,834 & $0,134^{* *}$ & 0,622 & $0,079^{* *}$ \\
4) CF & 1,137 & 0,879 & $0,061^{* *}$ & 0,886 & $0,041^{* *}$ & 0,838 & $0,039^{* *}$ & 0,686 & $0,118^{* *}$ & 0,853 & $0,032^{* *}$ & 0,761 & $0,192^{* *}$ \\
\hline
\end{tabular}

${ }^{*} p<0,05 ;{ }^{* *} p<0,01 \quad$ CF: Consciência fonêmica; NSR: Nomeação seriada rápida. 
compreendiam quatro passos. A idade cronológica e o QI verbal entraram na análise no primeiro e segundo passos, respectivamente, e as medidas de consciência fonêmica e de nomeação rápida entraram na equação no terceiro e quarto passos: em uma das análises, a consciência fonêmica entrou na equação no terceiro passo e a nomeação rápida no quarto; essa ordem foi invertida na outra análise. (4) Com esse procedimento, esperávamos determinar se cada uma dessas habilidades contribuía independentemente para a variação na habilidade de leitura ou escrita, isso é, se a contribuição de cada uma delas independia da contribuição da outra.

Como pode ser visto na Tabela 6 , tanto a consciência fonêmica, como a nomeação rápida, contribuíram variação independente para a maioria das medidas de leitura e escrita. A única exceção ocorreu para o teste de Produção de Escrita: não houve evidência de que a nomeação rápida contribuísse variação única para o desempenho nesse teste.

Também calculamos uma série de análises de regressão com o intuito de investigar a contribuição da consciência fonêmica e da nomeação rápida para o desempenho nos testes de Compreensão de Leitura, significativa de variação ao teste Gray de Leitura Oral. Nem a consciência fonêmica, nem a nomeação rápida adicionaram uma porção significativa de variação ao teste de Reconhecimento de Escrita, após havermos levado em consideração a variação na habilidade de reconhecimento de palavras escritas, além da variação na idade cronológica e na inteligência verbal.

Como mencionamos na introdução, alguns pesquisadores (por exemplo, McBride-Chang \& Manis, 1996; Meyer e cols., 1998) sugeriram que a nomeação rápida é mais importante no início da aquisição da leitura ou entre crianças com dificuldades de leitura. Em vista disso, calculamos uma série final de análises para investigar em que medida a variação atribuída à nomeação rápida ou à consciência fonêmica na nossa amostra interagia com a habilidade de leitura (presença de dificuldade $v$ s. ausência de dificuldade) e/ou com a idade cronológica. Isso foi feito através da inclusão de um termo de interação ao último conjunto de análises de regressão. Para os testes de compreensão de leitura, produção de escrita e leitura de pseudopalavras, o termo de interação avaliava se a consciência fonêmica interagia com a habilidade de leitura, a idade, ou com ambas. Para o teste de fluência de leitura,

Tabela 7. Variância nos Testes de Leitura e Escrita atribuída à Consciência Fonêmica e à Nomeação Seriada Rápida após o Controle de Diferenças na Idade, QI Verbal e no PIAT Leitura de Palavras

Variáveis Independentes Variável Dependente

\begin{tabular}{lcccccc}
\cline { 2 - 6 } & $g l$ & $\begin{array}{c}\text { Compreensão } \\
\text { de Leitura }\end{array}$ & $\begin{array}{c}\text { Reconhecimento } \\
\text { de Escrita }\end{array}$ & $\begin{array}{c}\text { Produção } \\
\text { de Escrita }\end{array}$ & $\begin{array}{c}\text { Gray Oral } \\
\text { Fluência de Leitura }\end{array}$ & $\begin{array}{c}\text { Leitura de } \\
\text { Pseudopalavras }\end{array}$ \\
Consciência Fonêmica & 1,139 & $0,009^{*}$ & 0,003 & $0,035^{*}$ & 0,002 & $0,062^{* *}$ \\
Nomeação Seriada & 1,138 & 0,004 & 0,003 & 0,000 & $0,038^{* *}$ & 0,003 \\
\hline
\end{tabular}

Reconhecimento de Escrita, Produção de Escrita, Leitura de Pseudopalavras, e no teste Gray de Leitura Oral, após o controle do efeito de variações no teste de Leitura de Palavras, além do controle de variações na idade cronológica e no QI verbal. Esse controle adicional foi incluído com o objetivo de investigar se a consciência fonêmica ou a nomeação seriada rápida contribuem variação para aquelas medidas mais específicas de leitura e escrita, variação essa que não possa ser explicada em termos da variação na habilidade de reconhecimento de palavras escritas. Os resultados dessas análises aparecem na Tabela 7. Como pode ser visto nessa tabela, a consciência fonêmica adicionou uma porção significativa de variação aos testes de Leitura de Pseudopalavras, de Produção de Escrita, e de Compreensão de Sentenças, enquanto que a nomeação rápida adicionou uma porção o termo de interação avaliava em que medida a nomeação seriada rápida interagia com a habilidade de leitura, a idade cronológica, ou com ambas essas variáveis.

Nenhuma das interações envolvendo a consciência fonêmica $(\mathrm{CF})$ contribuiu significativamente para a variação no teste de Compreensão de Leitura. Por outro lado, a interação CF X Idade contribuiu significativamente para a variação no teste de Leitura de Pseudopalavras [F (1, $138)=7,02, p<0,01]$. Finalmente, tanto a interação CF X Habilidade de Leitura $[F(1,138)=10,49, p<0,05]$ como a interação CF X Habilidade de Leitura X Idade $[F(1,138)$ $=4,92, p<.05]$ contribuíram para a variação no teste de Produção de Escrita.

Um exame dos dados revelou que a contribuição da consciência fonêmica para a leitura de pseudopalavras aumentou com a idade, tanto entre os participantes com 
dificuldades de leitura como entre aqueles sem dificuldades. A interação entre a consciência fonêmica e a habilidade de leitura obtida para o teste de Produção de Escrita resultou do fato de que a relação entre a consciência fonêmica e a produção de escrita foi mais forte entre os participantes com dificuldades de leitura do que entre aqueles sem dificuldades. Contudo, a diferença entre os participantes com e sem dificuldades em relação à correlação entre aquelas duas medidas foi particularmente pronunciada entre os participantes mais velhos, o que explica a interação entre a consciência fonêmica, a habilidade de leitura e a idade.

Todas as três interações envolvendo a nomeação seriada rápida (NSR) - isso é, a interação NSR X Idade $[F(1,137)=11,34, p<0,001]$, a interação NSR X Habilidade de Leitura $[F(1,137)=27,28, p<0,001]$ e, finalmente, a interação NSR X Habilidade de Leitura X Idade $[F(1,137)=13,66, p<0,001]-$ contribuíram significativamente para a variação no teste Gray de Leitura Oral. Embora a nomeação seriada rápida tenha apresentado uma contribuição significativa em ambos os grupos, sua contribuição foi maior entre os leitores com dificuldades. O efeito da idade pareceu restrito ao grupo de participantes com dificuldades de leitura. Nesse grupo, a contribuição da nomeação rápida para a fluência da leitura de textos diminuiu com a idade, o que explica a interação significativa entre a nomeação rápida, a habilidade de leitura, e a idade.

\section{Discussão}

Os nossos resultados estão de acordo com os resultados de vários estudos mostrando uma relação estreita entre a consciência fonêmica e a habilidade de leitura e escrita. Eles também replicaram os resultados de estudos anteriores ao mostrarem que a habilidade de nomeação seriada rápida contribui para a variação na leitura, e que essa contribuição independe da contribuição da consciência fonêmica. No entanto, os nossos resultados sugerem que, em relação à consciência fonêmica, a contribuição da nomeação seriada rápida para a habilidade de leitura e escrita é bastante modesta.

A única exceção a esse padrão ocorreu para o teste que avalia a rapidez e a correção da leitura de textos. Para esse teste, a contribuição da nomeação rápida foi mais pronunciada do que a da consciência fonêmica. De fato, após controlarmos o efeito de diferenças na habilidade de reconhecer palavras escritas, além do efeito de variações na idade e na inteligência verbal, apenas a nomeação seriada rápida adicionou uma porção significativa de variação ao desempenho no teste Gray de Leitura Oral. Esses resultados contrastam com os resultados obtidos para o teste de Compreensão de Leitura, de Produção de Escrita e de Leitura de Pseudopalavras. Apenas a medida de consciência fonêmica adicionou variação significativa ao desempenho nesses testes, após havermos levado em consideração a habilidade de os nossos participantes lerem palavras isoladas, isto é, descontextualizadas.

Esses resultados estão de acordo com a sugestão de que a nomeação seriada rápida e a consciência fonêmica contribuem de maneira diferente para a habilidade de leitura. Em particular, os resultados do presente estudo replicaram os resultados de outros estudos (ver, por exemplo, Manis e cols., 1996) mostrando uma conexão especial entre a consciência fonêmica e a habilidade de ler através da codificação fonológica. Os nossos resultados também replicaram os resultados de estudos anteriores (Cornwall, 1992; Morris e cols., 1998) em relação a existência de uma relação especial entre a nomeação seriada rápida e a habilidade de leitura fluente. Contudo, nossos resultados questionam a hipótese de que a habilidade de nomeação rápida seja especialmente importante para a aquisição da habilidade de codificação ortográfica (Bowers, 1995; Manis e cols., 1999). Conforme notamos acima, com exceção do teste de fluência de leitura, a nomeação seriada rápida contribuiu relativamente pouca variação para a habilidade de leitura e escrita. Isso ocorreu, independentemente de a medida de leitura (ou escrita) depender mais ou menos fortemente de habilidades de codificação fonológica (por exemplo, a leitura de pseudopalavras e a produção de escrita) ou ortográfica (por exemplo, o teste de reconhecimento da ortografia das palavras). Todas essas medidas mostraram uma conexão mais forte com a consciência fonêmica do que com a habilidade de nomeação seriada rápida. Esses resultados estão totalmente de acordo com a hipótese de que a habilidade de codificação fonológica é a base da habilidade de aprender a ortografia correta das palavras, até mesmo de palavras contendo correspondências letra-som irregulares (ver, por exemplo, Ehri, 1992; Frith, 1985; Gough \& Walsh, 1991).

Tampouco encontramos muita evidência de que o papel da habilidade de nomeação seriada rápida (ou da consciência fonêmica) é modulado pela habilidade de leitura. De fato, ficamos surpresos com a semelhança dos resultados encontrados para os indivíduos com e sem dificuldades de leitura. Da mesma maneira, apesar da ampla gama de variação na idade dos nossos participantes, o efeito da consciência fonêmica e da nomeação seriada rápida raramente interagiu com a idade. Como parece ter ocorrido para a habilidade de leitura, a 
diferença do impacto daquelas variáveis entre os participantes mais jovens e os mais velhos era, quase sempre, uma diferença de natureza quantitativa e não qualitativa.

Em suma, os resultados do presente estudo são consistentes com a hipótese de que os processos fonológicos desempenham um papel importante na aquisição da leitura em um sistema de escrita alfabético. Uma vez que as letras do alfabeto representam fonemas, não é surpreendente que a habilidade de identificar, segmentar e manipular fonemas correlacione-se com a aquisição de habilidades alfabéticas de leitura e escrita. Por outro lado, o mecanismo subjacente à correlação entre a habilidade de nomear rapidamente estímulos visuais familiares e a aquisição da leitura e da escrita não é, de maneira nenhuma, óbvio. A relação relativamente forte entre aquela habilidade e a leitura oral de textos encontrada no presente estudo pode ser explicada em termos do fato de que, como acontece com o RAN e o RAS, a rapidez é um componente importante do teste Gray de Leitura Oral. Por outro lado, qualquer uma entre uma longa lista de habilidades - atenção prolongada, codificação visual, coordenação de informação visual e fonológica, etc. - poderia explicar as correlações modestas encontradas entre a nomeação seriada rápida e as várias medidas de habilidade de leitura. Nossos resultados são certamente favoráveis à investigação dos mecanismos subjacentes à contribuição da nomeação seriada rápida para a habilidade de leitura. Contudo, eles também sugerem que, qualquer que seja a natureza desses mecanismos, eles desempenham um papel relativamente modesto na aquisição da leitura e da escrita em um sistema alfabético de escrita.

\section{Notas}

1) Para uma descrição mais detalhada da amostra, ver Pennignton, Cardoso-Martins, Green \& Lefly, no prelo. 2) Para o RAN e o RAS, os escores foram inicialmente transformados em logs. Esse procedimento é, em geral, utilizado com dados de latência uma vez que esses dados não são usualmente distribuídos normalmente.

3) Os valores negativos encontrados para as correlações entre as medidas de nomeação seriada rápida e as medidas de leitura e escrita refletem o fato de que quanto menor o tempo de latência no RAN e no RAS maior os escores nos teste de leitura e escrita.

4) $O$ número relativamente pequeno de correlações significativas entre, por um lado, o QI e, por outro, as medidas de leitura e escrita e as medidas experimentais (ver Tabela 5), pode ser explicado em termos do fato de que o mesmo escore bruto em um teste de habilidade tem obviamente significados diferentes em idades diferentes. De fato, quando a variação na idade cronológica foi levada em consideração, o QI em geral, mas particularmente o QI Verbal, correlacionou-se significativamente com as medidas de leitura e escrita e com as medidas de consciência fonêmica e nomeação seriada rápida.

\section{Referências}

Bowers, P. G. (1995). Tracing symbol naming speed's unique contributions to reading disability over time. Reading and Writing: An Interdisciplinary Journal, 7, 189-216.

Bowers, P. G. \& Wolf, M. (1993). Theoretical links among naming speed, precise timing mechanisms and orthographic skill in dyslexia. Reading and Writing: An Interdisciplinary Journal, 5, 69-85.

Brady, S. A. \& Shankweiler, D. P. (1991). Phonological processes in literacy: A tribute to Isabelle Y. Liberman. Illsdale, NJ: Lawrence Erlbaum Associates.

Bruck, M. (1992). Persistence of dyslexics' phonological awareness deficits. Developmental Psychology, 28, 874-887.

Cornwall, A. (1992). The relationship of phonological awareness, rapid naming, and verbal memory to severe reading and spelling disability. Journal of Learning Disability, 25, 532-538.

Denckla, M. \& Rudel, R. (1976). Rapid Automatized Naming (RAN): Dyslexia differentiated from other learning disabilities. Neuropsychologia, 14, 471-479.

Dunn, L. M. \& Markwardt, F. C. (1970). Examiner's Manual: Peabody Individual Achievement Test. Circle Pines, MN: American Guidance Service.

Ehri, L. (1992). Reconceptualizing the development of sight word reading and its relationship to recoding. Em P. Gough, L. Ehri \& R. Treiman (Orgs.), Reading acquisition (pp. 107-144). Hillsdale, NJ: Erlbaum.

Frith, U. (1985). Beneath the surface of developmental dyslexia. Em K. Patterson, J. Marshall \& M. Coltheart (Orgs.), Surface dyslexia: Neuropsychological and cognitive studies of phonological reading (pp. 301-330). Hillsdale: Lawrence Erlbaum Associates.

Goswami, U. \& Bryant, P. (1990). Phonological skills and learning to read. Hove, Inglaterra: Erlbaum.

Gough, P. L. \& Walsh, M. A (1991). Chinese, Phoenicians, and the orthographic cipher of English. Em S. Brady \& D. P. Shankweiler (Orgs.), Phonological processes in literacy: A tribute to Isabelle Y. Liberman (pp. 199-209). Illsdale, NJ: Lawrence Erlbaum Associates.

Jastak, S. \& Wilkinson, G. S. (1984). WRAT-R - Wide Range Achievement Test. Wilmington, Delaware: Jastak Associates, Inc.

Manis, F. R., Seidenberg, M. S. \& Doi, L. M. (1999). Em Dick RAN: Rapid naming and the longitudinal prediction of reading subskills in first and second graders. Scientific Studies of Reading, 3, 129-157.

McBride,-Chang, C. \& Manis, F. R. (1996). Structural invariance in the associations of naming speed, phonological awareness, and verbal reasoning in good and poor readers: A test of the double deficit hypothesis. Reading and Writing An interdisciplinary Journal, 8, 323-339.

Meyer, M. S., Wood, F. B., Hart, L. A. \& Felton, R. H. (1998). Selective predictive value of rapid automatized naming in poor readers. Journal of Learning Disabilities, 31, 106-117.

Morris, R., Stuebing, K., Fletcher, J., Shawitz, S., Lyon, R., Shankweiler, D., Katz, L., Francis, D. \& Shawitz, B. (1998). Subtypes of reading disability: A phonological core. Journal of Educational Psychology, 90, 347-373.

Olson, R. K., Forsberg, H. \& Wise, B. (1994). Genes, environment, and the development oforthographic skills. Em V. W. Berninger (Org.), The varieties of orthographic knowledge I: Theoretical and developmental issues (pp. 27-71). Dordrecht, Holanda: Kluwer Academics.

Pennington, B. F., McCabe, L. L., Smith, S. D., Lefly, D. L., Bookman, M. O., Kimberling, W. J. \& Lubs, H. A. (1986). Spelling errors in adults with a form of familial dyslexia. Child Development, 57, 1001-1013. 
Pennington, B. F., Lefly, D. L., Van Orden, G. C., Bookman, M. O. \& Smith, S. D. (1987). Is phonology bypassed in normal or dyslexic development? Annals of Dyslexia, 37, 62-89.

Pennington, B. F., Van Orden, G. L., Smith, S.D., Green, P. A. \& Haith, M. M. (1990). Phonological processing skills and deficits in adult dyslexics. Child Development, 61, 1753-1778.

Pennington, B. F., Cardoso-Martins, C., Green, P. A. \& Lefly, D. L. (no prelo). Comparing the phonological and double-deficit hypotheses for developmental dyslexia. Reading and Writing: An Interdisciplinary Journal.

Pennington, B. F. \& Lefly, D. L. (no prelo). Early reading development in children at family risk for dyslexia. Reading and Writing: An Interdisciplinary Journal.

Stanovich, K. E. (1988). The dyslexic and the garden-variety poor reader: The phonological-core variable-difference model. Journal of Learning Disabilities, 21, 590-604.

Stanovich, K. E. (1994). Annotation: Does dyslexia exist? Journal of Child Psychology and Psychiatry, 35, 579-595.

Stanovich, K. E. \& Siegel, L. S. (1994). Phenotypic Performance Profile of Children with Reading Disabilities: A regression based test of the phonological-core variable difference model. Journal of Educational Psychology, 86, 24-53.

Torgesen, J. K., Wagner, R. K., Rashotte, C. A., Burgess, S. \& Hecht, S.(1997). Contributions of phonological awareness and rapid automatic naming ability to the growth of word-reading skills in second- to fifth-grade children. Scientific Studies of Reading, 1, 161-185.
Wagner, R.K., Torgesen, J.K., Rashotte, C.A., Hecht, S.A., Barker, T.A., Burgess, S.R., Donahue, J. \& Garon, T. (1997). Changing relations between phonological processing abilities and word-level reading as children develop from beginning to skilled readers: A 5-year longitudinal study. Developmental Psychology, 33, 468-479.

Wechsler, D. (1974). Wechsler Intelligence Scale for Children - Revised. San Antonio, TX: The Psychological Corporation.

Wiederholt, J. L. \& Bryant, B. R. (1992). Gray Oral Reading Tests (3a ed.). Austin, TX: Pro-ed.

Wolf, M., Bally, H. \& Morris, R. (1986). Automaticity, retrieval processes, and reading: An longitudinal study in average and impaired readers. Child Development, 57, 988-1005.

Wolf, M. \& Bowers, P. G. (1999). The double-deficit hypothesis for the developmental dyslexias. Journal of Educational Psychology, 91, 415-438.

Sobre os autores

Claudia Cardoso-Martins é Professora Titular do Departamento de Psicologia da Universidade Federal de Minas Gerais, Coordenadora do Laboratório de Pesquisas em Desenvolvimento Cognitivo e da Linguagem.

Bruce F. Pennington é Professor Titular do Departamento de Psicologia da Universidade de Denver, Colorado, Coordenador do Laboratório de Neuropsicologia do Desenvolvimento.

Recebido: 28/08/2000

Revisado: 23/01/2001

Aceite final: 12/06/2001 